\title{
A New Scuffing Test Using Contra-Rotation
}

\author{
Marc Ingram, Clive Hamer and Hugh Spikes \\ Corresponding author : Marc Ingram; drmarcingram@gmail.com
}

Published; Wear 328-329, 229-240, (2015).

\begin{abstract}
The mode of lubricant failure known as scuffing provides a significant design constraint in high sliding gears, cams and metal cutting and forming processes. It is therefore important to have an effective test method to measure the scuffing resistance of lubricant formulations. In most existing scuffing bench tests, a moving surface is rubbed against a stationary one at a fixed sliding speed and the load at which scuffing occurs is determined. This approach has two disadvantages. One is that wear of the stationary surface can lead to a large decrease in effective contact pressure during a test. The second is that viscous lubricants often generate significant elastohydrodynamic films at the sliding speeds employed. This means that the scuffing tests measure a complex combination of the influence of the fluid and boundary film-forming properties of the lubricant on scuffing rather than reflecting solely the influence of lubricant formulation.

This paper describes a new scuffing test method in which the two metal surfaces are rubbed together in mixed rolling-sliding with the two surfaces moving in opposite directions with respect to the contact, i.e. in contra-rotation. This enables the sliding speed to be decoupled from the entrainment speed so that the scuffing properties of a lubricant can be determined in boundary lubrication conditions over a wide range of sliding speeds. Also, because both surfaces move relative to the contact, wear is distributed and this minimises changes in contact pressure during a test.
\end{abstract}

\section{BACKGROUND}

Scuffing (often termed scoring in the United States) occurs in lubricated contacts when the lubricating film present in the contact suddenly collapses, resulting in solidsolid adhesion with a consequent very rapid increase in friction and extensive surface damage. It occurs in contacts operating at high pressures and sliding speeds and was first documented in the 1920s when automotive hypoid gears were introduced. This episode led to the development of extreme pressure additives, initially based on lead, sulphur and chlorine, specifically designed to prevent scuffing [1]. Scuffing is still a design barrier in many high-sliding gear configurations, in sliding cam-follower systems and in metal-cutting and forming processes. 
Numerous test methods have been designed to determine the conditions at which scuffing occurs and thus to measure the scuffing resistance of lubricants and materials and to explore the mechanisms of scuffing. The first scuffing tests such as the four ball method originated in the 1930s and were developed to address the hypoid gear scuffing problem and to assist in the development of extreme pressure additives [2].

One important limitation of the four ball test [3] and the more modern Timken test [4] is that they involve a moving surface rubbing against a stationary counterpart. This generally results in considerable wear on the stationary surface within the contact, which leads to a large increase in effective contact area and thus to a considerable reduction in contact pressure during a test. This means that systems which suffer high wear often require higher loads to scuff than those which have low wear, a factor that can obscure their intrinsic scuffing resistance. This limitation was recognised in the 1930s, where it was noted that the SAE Extreme Pressure Machine, a disc machine in which both surfaces move relative to the contact, gave more useful scuffing information than tests with one stationary surface $[1,5]$.

It is important to appreciate that scuffing only takes place when all of the protective lubricant films that separate the lubricated rubbing surfaces are destroyed by the rubbing action, i.e. both elastohydrodynamic films due to liquid entrainment and boundary films resulting from lubricant-surface interactions. The penultimate step before scuffing is the removal of the metal oxide film, to expose the nascent metal surface. Since scuffing normally occurs at high sliding speeds, an elastohydrodynamic (EHD) film is often present and the process of scuffing thus involves first the collapse of this fluid film, then the loss of any micro-EHD films present at asperity conjunctions and finally the destruction of any boundary lubricating films. Any of these three films can provide the critical performance barrier to scuffing. This is reflected in de Gee's "transition diagram" [6,7], as illustrated in Figure 1. This maps the scuffing response of a specific lubricated system in terms of sliding speed and applied load. Three transitions are recognised. At low sliding speeds (on the left hand side of Figure 1), as the load is increased, first the EHD (or micro-EHD) film collapses (transition from I to II), generally resulting in an increase in friction and wear. Scuffing does not occur however, since a boundary lubricating film is still present. Then as the applied load is increased further, the boundary film collapses at the transition from II to III and scuffing occurs. At high sliding speeds, (on the right of Figure 1), as soon as the EHD film collapses the contact conditions are so severe that any boundary film is also immediately destroyed, so the system passes straight from EHD lubrication conditions to scuffing, i.e. from I to III. 


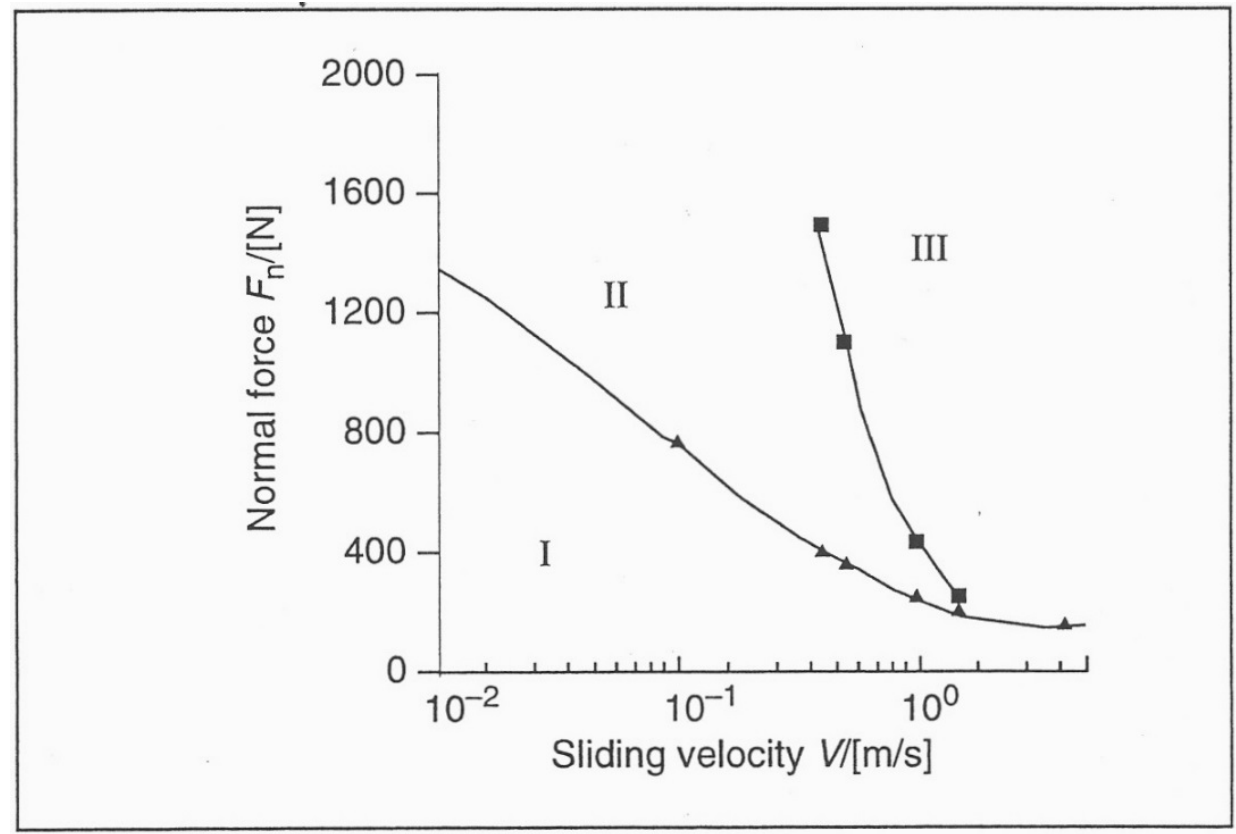

Figure 1: Transition diagram reproduced from [6] showing the conditions for I EHL lubrication, II boundary lubrication and III scuffing

This diagram reflects an inherent complication in scuffing tests which will be addressed in this paper; that depending on the contact conditions such tests may be measuring quite different things, either the strength of the fluid film or that of the boundary film.

This complication has also imbued research to explore the mechanisms of scuffing. Many scuffing mechanisms have been proposed, as reviewed by Bowman and Stachowiak [8]. The earliest was the flash temperature hypothesis of Blok in the 1940s, which proposed that scuffing occurs when the temperature within the contact reaches some critical value [9]. Although this hypothesis does not require any assumption about the mechanism of film breakdown, Blok suggested the critical temperature corresponded to the breakdown temperature of the boundary film present [10]. Once the existence and properties of elastohydrodynamic lubrication had become established, however, it was realised that scuffing requires the collapse of any EHD film present and this led to models by Dyson and co-workers which proposed that scuffing resulted from loss of film pressure due to heating of the lubricant and the asperities in the contact inlet [11-12]. EHD film collapse also forms the basis of models in which catastrophic starvation results from accumulation of wear debris in the inlet [13]. Recently there has been considerable focus on the behaviour of the rubbing solid sub-surfaces during rubbing and models based on metallic transformation processes initiated by the rapid application of pressure, shear stress and temperature have been developed [14]. It is noteworthy that all the above 
interpretations of scuffing focus on different stages in the, presumably sequential, film breakdown process.

The aim of the current paper is not to explore the various proposed scuffing mechanisms but rather to describe an experimental test approach which should help both to measure the inherent scuffing-resistance properties of lubricants and to explore mechanism of scuffing in a systematic fashion. This is timely since engine lubricants are currently undergoing major formulation changes, driven by environmental concerns, which involve a reduction in concentrations of the additives that presently control valve train scuffing. There is also a continuing trend to reduce the size of engineered components such as gears so as to lower vehicle mass, and this is resulting in increased contact pressures and thus stronger demands on the lubricant performance.

\section{PRINCIPLE OF TEST METHOD}

An often unrecognised problem in scuffing and wear testing is that, when one surface is stationary and the other moving, as is the case in most scuffing and wear tests, any increase in sliding speed also leads to a corresponding increase in entrainment speed and thus EHD film thickness.

If $u_{1}$ and $u_{2}$ are the speeds of the two surfaces with respect to the contact, the sliding speed, $u_{s}$ is $\left|u_{1}-u_{2}\right|$ and the entrainment, or mean rolling speed, $U$ is $\left(u_{1}+u_{2}\right) / 2$. The slide roll ratio, $S R R$, is defined as the ratio of the sliding speed to the entrainment speed and is thus;

$$
\operatorname{SRR}=\frac{\left|u_{1}-u_{2}\right|}{\left(u_{1}+u_{2}\right) / 2}
$$

In a sliding contact with one surface stationary, $u_{2}=0$, so that, from equation 1 , the slide roll ratio has the value 2 . Therefore in this type of rubbing contact the entrainment speed is always half the sliding speed. In elastohydrodynamic lubrication, the EHD film thickness, $h$ is given by

$$
h \approx k(U \eta)^{0.67}
$$

where $\eta$ is the dynamic viscosity [15]. Thus any increase in sliding speed must be accompanied by a corresponding increase in EHD film thickness, a relationship that only breaks down when heat generation due to sliding is so great as to reduce the effective viscosity of the lubricant in the contact inlet. 
The above means that in most scuffing tests, as the sliding speed is progressively increased, the thickness (and thus "strength") of the EHD film also increases, greatly complicating our interpretation of scuffing results obtained over a range of speeds. It also means that fluids of higher viscosity will tend to show intrinsically higher resistance to scuffing than those of lower viscosity, regardless of the presence of boundary lubricating additives.

One way round this problem was suggested in a little-known paper by Blok in 1946 [16] and is adopted in the current study. He employed a rolling-sliding contact in which the two rubbing surfaces move in opposite directions relative to the contact, so that $u_{1}$ and $u_{2}$ have opposite signs. This enables the entrainment speed and the sliding speed to be decoupled so that high sliding speed can be combined with very low entrainment speed and thus negligible fluid film entrainment. The test thus focuses entirely on the effectiveness of lubricant additives and boundary films in preventing scuffing.

Figure 2 reproduces a figure from Blok's original paper to demonstrate the principle of the approach. He used a twin disc machine and rotated the two discs at the same speed in opposite directions, to give nominally zero hydrodynamic entrainment (Blok's work preceded knowledge of EHD lubrication so he analysed his system in terms of isoviscous-elastic hydrodynamic lubrication theory).
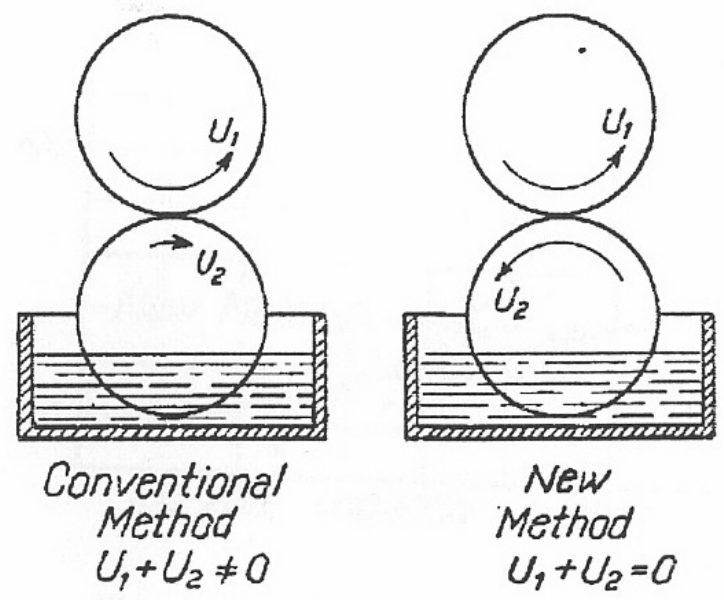

Figure 2: A diagram introducing the contra-rotating method, reproduced from Blok [16]

Blok used this approach to investigate the effect of lubricant viscosity on scuffing performance for a set of mineral base oils. His results are summarised in Figure 3 taken from [16]. His "conventional method" plot shows scuffing load against lubricant viscosity for tests in which the slide roll ratio was 1.75 (i.e. both surfaces moving in the same direction, but one much slower than the other). The "New Method" shows results for the same set of lubricants when the discs contra-rotate with 
respect to the contact to give at zero nominal hydrodynamic film thickness. In the first case there is a marked increase in the load needed to cause scuffing for high viscosity lubricants, presumably because the EHD film becomes progressively thicker as viscosity is increased at the constant test speed used. In contra-rotating conditions, however, the scuffing load increases only slowly and monotonically with viscosity. Blok ascribed this increase to the higher viscosity minerals oils having larger proportions of polar, surface active species able to provide boundary film protection.

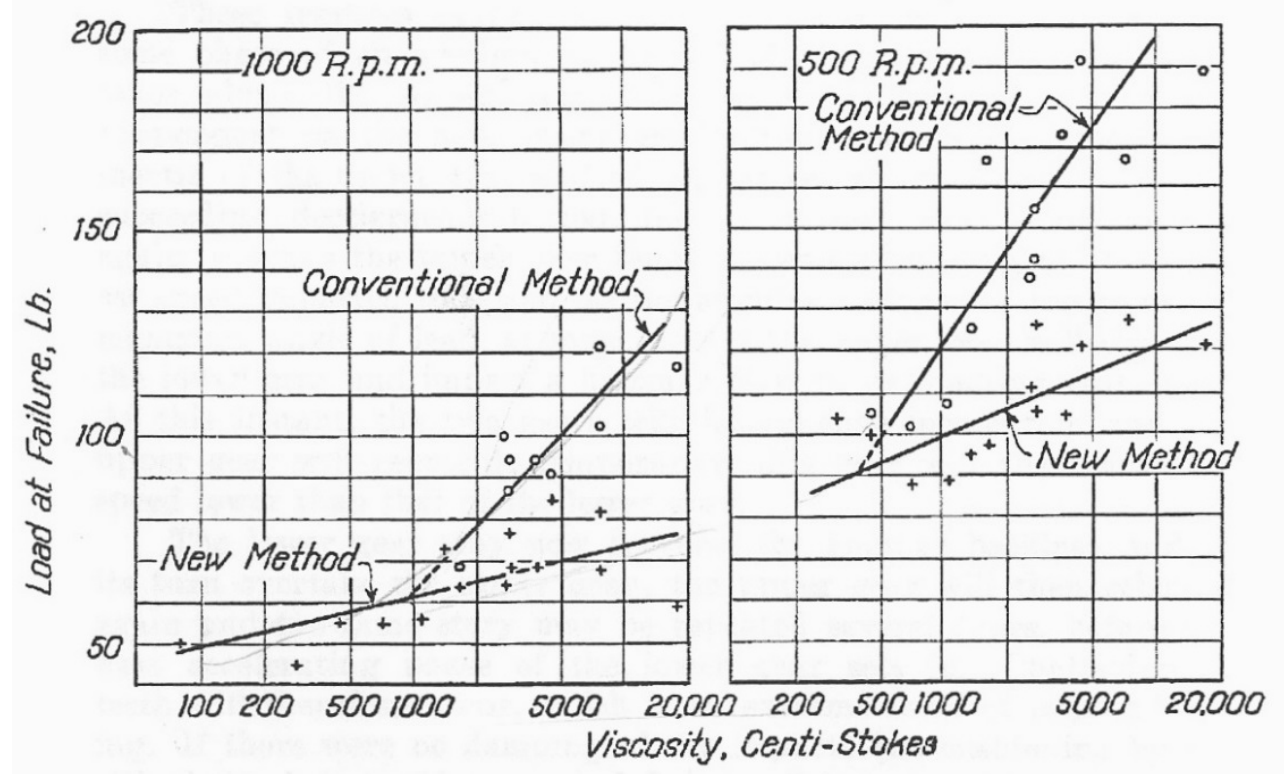

Figure 3: Load at scuffing failure for a range of mineral oils with varying viscosity reproduced from Blok [16]

It is clear from Blok's work described above that the use of contra-rotation provides a simple and elegant means of separating the influence of lubricant formulation on scuffing from that of lubricant viscosity and it is quite surprising that the approach has not been widely adopted. The authors could find no later work that has used the same principle to investigate scuffing, although an alternative way of decoupling entrainment and sliding speed, by varying the rotational axis of the rotating bodies has been described by Wedeven [17]. The authors have also recently described the use of contra-rotation to produce an accelerated mild wear test [18].

\section{DETAILS OF TEST METHOD}

The current study uses a ball-on-disc contact rather than the twin-disc method of Blok. A mini-traction machine (MTM), manufactured by PCS Instruments is employed in this study and is shown schematically Figure 4. A ball is loaded and rotated against the flat surface of a rotating disc, both bodies being driven independently. The ball shaft is tilted so as to produce nominally zero-spin in the contact and a load cell is attached to the ball shaft bearing housing to provide a 
measurement of friction force. The disc is immersed in lubricant held at a controlled temperature. The MTM is a fully computer-controlled device and it is possible to vary the load, the temperature and the rotational speed of both ball and disc while monitoring friction over a programmed test sequence. It is also possible to rotate the ball and disc in either direction, and thus produce a wide range of slide-roll ratios, from pure rolling to contra-rotation with zero entrainment speed.

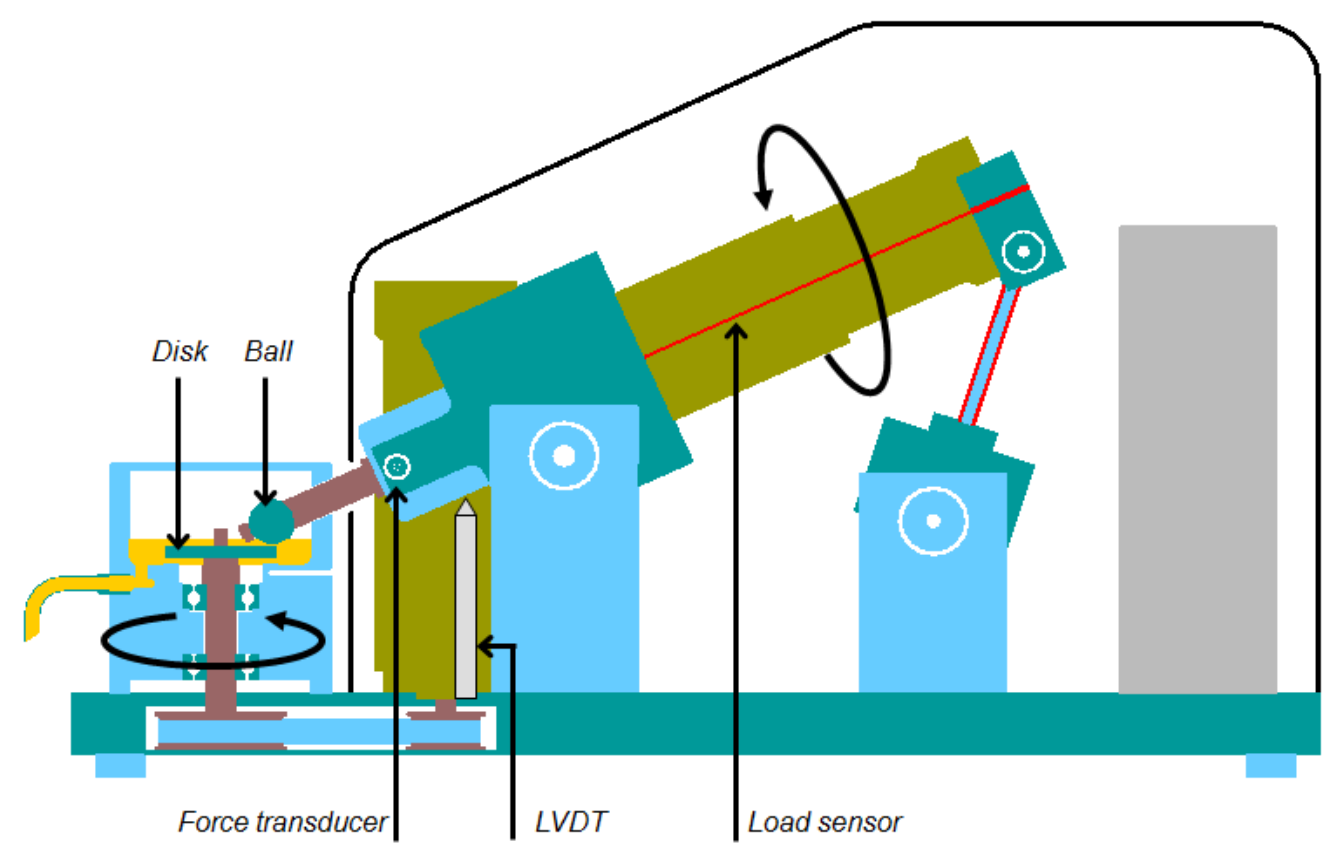

Figure 4: A schematic diagram of the ball-on-disc tribometer, Mini-traction machine (PCS Instruments)

Using the new method it is possible to increase the sliding speed or the applied load throughout the test to determine the critical conditions for scuffing. Examples of the results given under both conditions are shown in Figures 5 and 6. Figure 5 shows a test with a constant load of $30 \mathrm{~N}$, and the sliding speed is increased stepwise until scuffing occurs at $0.2 \mathrm{~m} / \mathrm{s}$. Figure 6 shows a test where the entrainment and sliding speed are constant, the load is increased stepwise until scuffing occurs at $20 \mathrm{~N}$ load. A large and sudden increase in the measured friction is detected at the onset of scuffing, along with increased vibration and audible sound. In the current work only constant load/increasing speed tests were employed, the reasons for which are clarified in the discussion.

A scuffing event was defined as a short sharp increase in the friction coefficient to above 0.25 for two or more seconds. The test surfaces were checked visually using a microscope to confirm scuffing had occurred at the end of the test. 


\section{Ramp Speed Test}

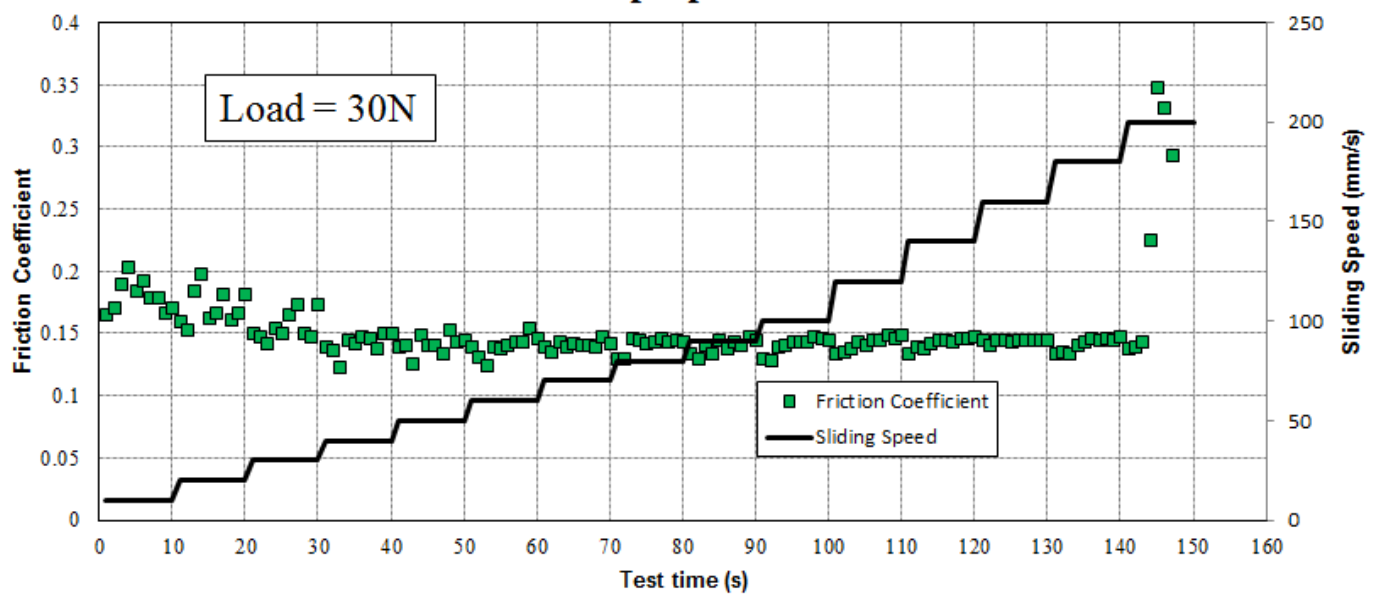

Figure 5: The measured friction coefficient in a test with the sliding speed increasing in a step-wise fashion

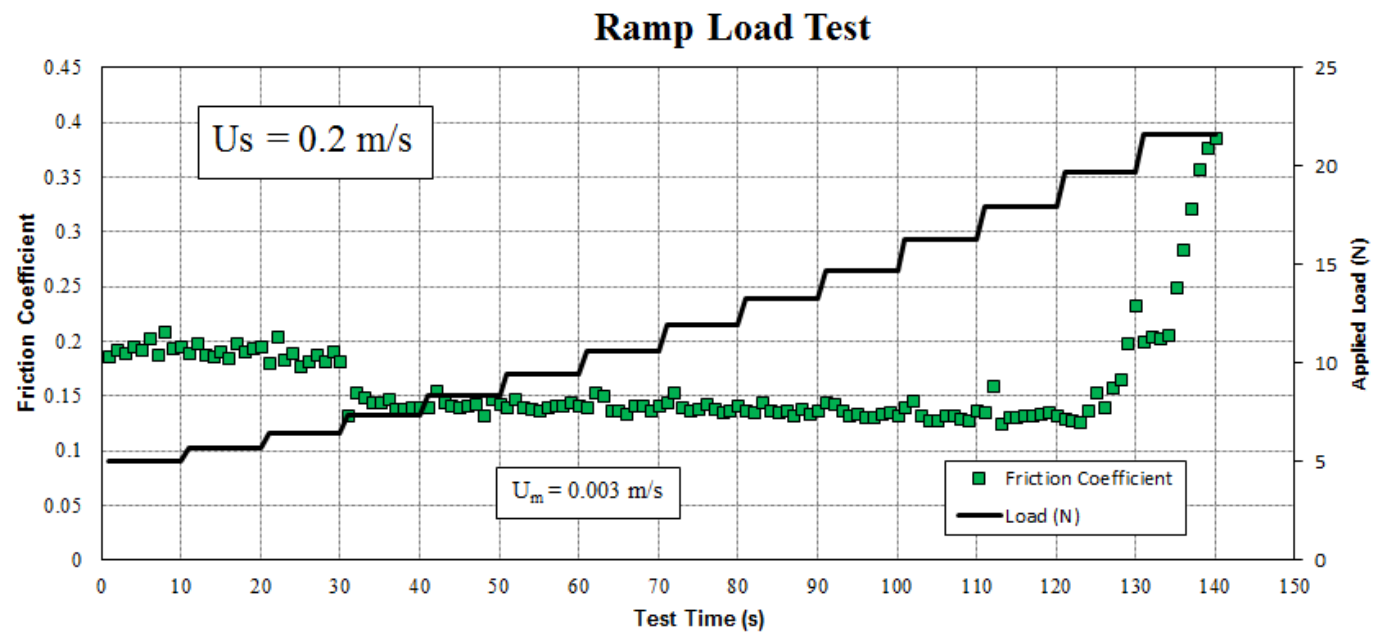

Figure 6: The measured friction coefficient in a test with the load increasing in a step-wise fashion

Two test sequences were employed; a "boundary" (Table 1) and "mixed" (Table 2) lubrication scuffing test. Both test sequences are similar in nature but employ different entrainment speeds. A fixed low value of entrainment speed of $U=0.003$ $\mathrm{m} / \mathrm{s}$ was employed for the boundary lubrication test. This is contrary to the zero entrainment speed suggested by Blok [16] (i.e. both surface moving with exactly the same speed in opposite directions) since in practice the latter is impossible to achieve precisely and it was considered better to have a very small, controlled value than an indeterminate one. An entrainment speed of $U=0.20 \mathrm{~m} / \mathrm{s}$ was employed for the mixed lubrication regime scuffing test.

The variation of the sliding speed sequence employed for both tests is shown in Figure 7. This was arrived at after some experimentation to determine conditions 
which encompassed the scuffing performance of both additive-free and formulated oils [19].

Table 1. Boundary lubrication regime scuffing test

\begin{tabular}{|l|c|c|c|}
\hline & Entrainment speed (m/s) & Sliding speed (mm/s) & Duration (s) \\
\hline Run-in & 0.003 & 0.01 & 600 \\
\hline Testing stage & 0.003 & Varies & 10 \\
\hline Rest stage & 0.1 & 0 & 30 \\
\hline
\end{tabular}

Table 2. Mixed lubrication regime scuffing test

\begin{tabular}{|l|c|c|c|}
\hline & Entrainment speed (m/s) & Sliding speed (m/s) & Duration (s) \\
\hline Run-in & 0.2 & 0.3 & 600 \\
\hline Testing stage & 0.2 & Varies & 10 \\
\hline Rest stage & 0.1 & 0 & 30 \\
\hline
\end{tabular}

The variation of the sliding speed sequence employed for both tests is shown in Figure 7. This was arrived at after some experimentation to determine conditions which encompassed the scuffing performance of both additive-free and formulated oils [19].

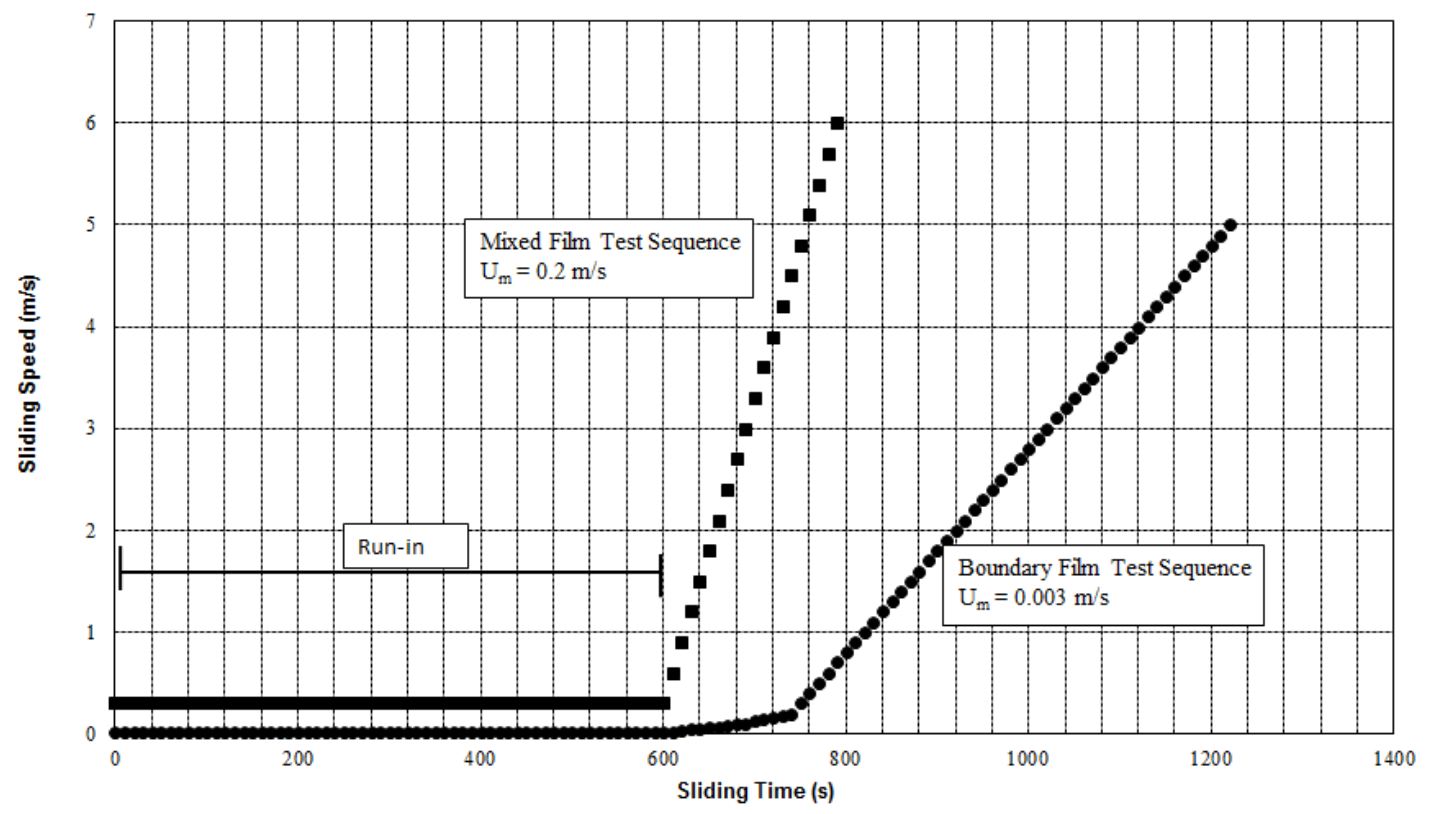

Figure 7: The variation of the sliding speed of the two test sequences (rest stages omitted) 
A new, freshly-cleaned ball and disc were used for each test. After assembling the test rig, the temperature was raised to its set value with the ball and disc rotating but unloaded and then load was applied and 10 minutes run-in carried out at very low sliding speed. Then the sliding speed was raised in a series of 10 second stages, separated by 30 seconds, pure rolling stages. The latter were intended to allow cooling of the test surfaces back to the test temperature $\left(120^{\circ} \mathrm{C}\right)$ after any frictional heating during the testing stages. The temperature of the lubricant was monitored during the tests and did not vary more than $\pm 3{ }^{\circ} \mathrm{C}$. The friction measured during the rolling stages is omitted in the presentation of the results.

In all tests, balls and disc of AISI 52100 steel were used. The mechanical properties of these test specimens are given in Table 3 .

The MTM can apply a controlled load in the range 1 to $75 \mathrm{~N} \pm 0.1 \mathrm{~N}$, corresponding to a maximum Hertz contact pressure range of 0.3 to $1.25 \mathrm{GPa}$. Table 4 contains the conversion from applied load to nominal contact pressure for this method, presented for the reader's convenience.

\begin{tabular}{|l|c|c|}
\hline \multicolumn{3}{|l|}{ Table 3. Ball and disc mechanical properties } \\
\hline & Ball & Disc \\
\hline Elastic modulus (GPa) & 207 & 207 \\
\hline Poisson's ratio & 0.3 & 0.3 \\
\hline Hardness (Hv) & $850 \pm 15$ & $760 \pm 15$ \\
\hline Roughness Ra (nm) & $<20$ & $10 \pm 4$ \\
\hline
\end{tabular}

Table 4. Contact pressure on MTM2

\begin{tabular}{|l|l|l|l|l|l|l|l|}
\hline Load (N) & 5 & 10 & 20 & 30 & 40 & 50 & 75 \\
\hline Contact pressure (GPa) & 0.50 & 0.65 & 0.82 & 0.94 & 1.03 & 1.09 & 1.25 \\
\hline
\end{tabular}

Five test oils are used to validate this technique; these are summarised in Table 5.

Three different base oils are used, a Group I, III and IV oil. These base oils have a similar viscosity but different concentrations of sulphur compounds. Two commercial additives are used; a long chain amide friction modifier (FM) which was blended in the Group III base oil, and a sulphurised isobutylene extreme pressure (EP) additive, which was blended in the Group I base oil. 


\begin{tabular}{|c|c|c|c|c|c|}
\hline $\begin{array}{l}\text { Oil } \\
\text { Name }\end{array}$ & Comments & $\begin{array}{l}\text { Sulphur } \\
\text { content }\end{array}$ & $\begin{array}{l}\text { Viscosity } \\
120^{\circ} \mathrm{C} \\
\text { calc. (cP) }\end{array}$ & $\begin{array}{l}\text { Film thickness } \\
\text { at } U_{m}=0.003 \\
\text { m/s calc. }(\mathrm{nm})\end{array}$ & $\begin{array}{l}\text { Film thickness } \\
\text { at } U_{m}=0.2 \\
\mathrm{~m} / \mathrm{s} \text { calc. }(\mathrm{nm})\end{array}$ \\
\hline Group I & $\begin{array}{l}\text { SN150 } \\
\text { base oil }\end{array}$ & $\begin{array}{c}0.25 \% \\
w t\end{array}$ & 3.5 & 1 & 13 \\
\hline $\begin{array}{c}\text { Group } \\
\text { III }\end{array}$ & Nexbase 3043 & $<5 \mathrm{ppm}$ & 3.0 & 1 & 12 \\
\hline $\begin{array}{c}\text { Group } \\
\text { IV }\end{array}$ & PAO 4 & $\sim 0$ & 2.9 & 1 & 12 \\
\hline $\begin{array}{c}\text { Group } \\
\text { III + FM }\end{array}$ & $\begin{array}{c}\text { Long chain } \\
\text { amide } \\
0.5 \% \text { wt in } \\
\text { Nexbase } 3043\end{array}$ & $<5 \mathrm{ppm}$ & 3.0 & 1 & 12 \\
\hline $\begin{array}{l}\text { Group I } \\
+\mathrm{EP}\end{array}$ & $\begin{array}{l}\text { Sulphurised } \\
\text { isobutylene } \\
\text { additive in } \\
\text { SN150 }\end{array}$ & $1 \% \mathrm{wt}$ & 3.5 & 1 & 13 \\
\hline
\end{tabular}

The data is presented in its entirety, i.e. no test results were excluded as outliers. The statistical variation is given and investigated in the Discussion section.

\section{RESULTS}

The raw friction values measured during the boundary lubrication scuffing test $(U=$ $0.003 \mathrm{~m} / \mathrm{s}$ ) for the Group I base oil are shown in Figure 8. Example results are shown for the 30,20, 10 and $5 \mathrm{~N}$ load tests, the lower pressure tests requiring higher sliding speeds for scuffing to occur. Figure 9 shows the friction measured during the mixed lubrication scuffing test $(U=0.2)$ for the same oil at 50,30 and $10 \mathrm{~N}$ load. Scuffing is indicated in both tests by a sudden increase in friction. The conditions (sliding speed and contact pressure) that induce scuffing for the Group I base oil in the boundary and mixed lubrication scuffing tests are collated in Figure 10. In this figure the pair of curved lines are included simply to emphasise the two different sets of test conditions. Increasing the entrainment speed from 0.003 to $0.2 \mathrm{~m} / \mathrm{s}$ has a marked effect on the pressure and sliding speeds required to induce scuffing. The error bars show the maximum and minimum sliding speeds to induce scuffing at that particular load. Although the shape of Figure 10 appears similar to de Gee's transition diagram shown in Figure 1, it is, in fact quite different since in De Gee's diagram the entrainment speed increased at increasing sliding speed, while in Figure 10 the two 
curves are at fixed entrainment speeds. Both curves in Figure 10 represent transitions from de Gee's zones II to III but at different entrainment speeds.

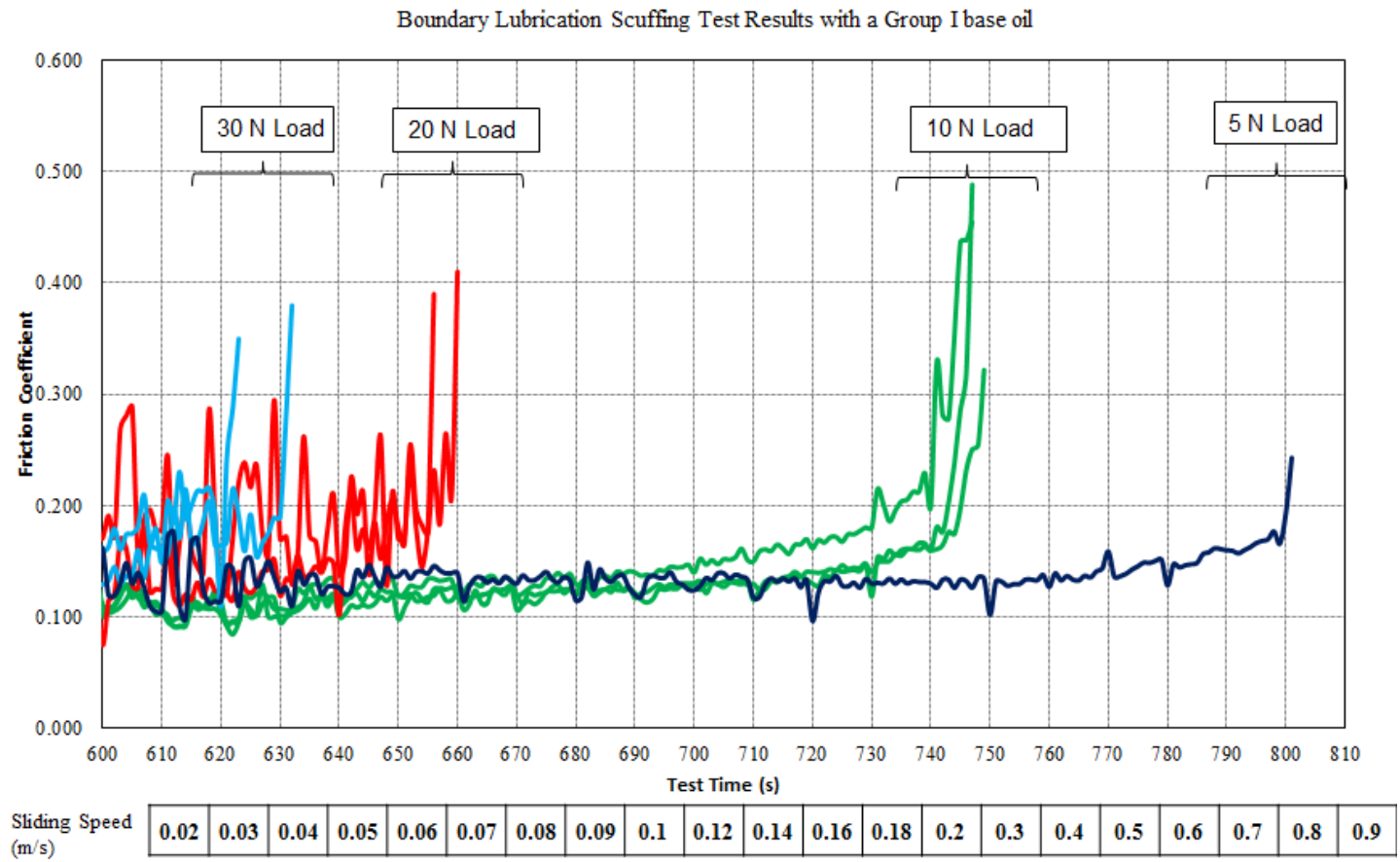

Figure 8: Example of the friction force measured during the boundary scuffing test at $30,20,10$ and $5 \mathrm{~N}$ load (repeat test are shown in the same colour)

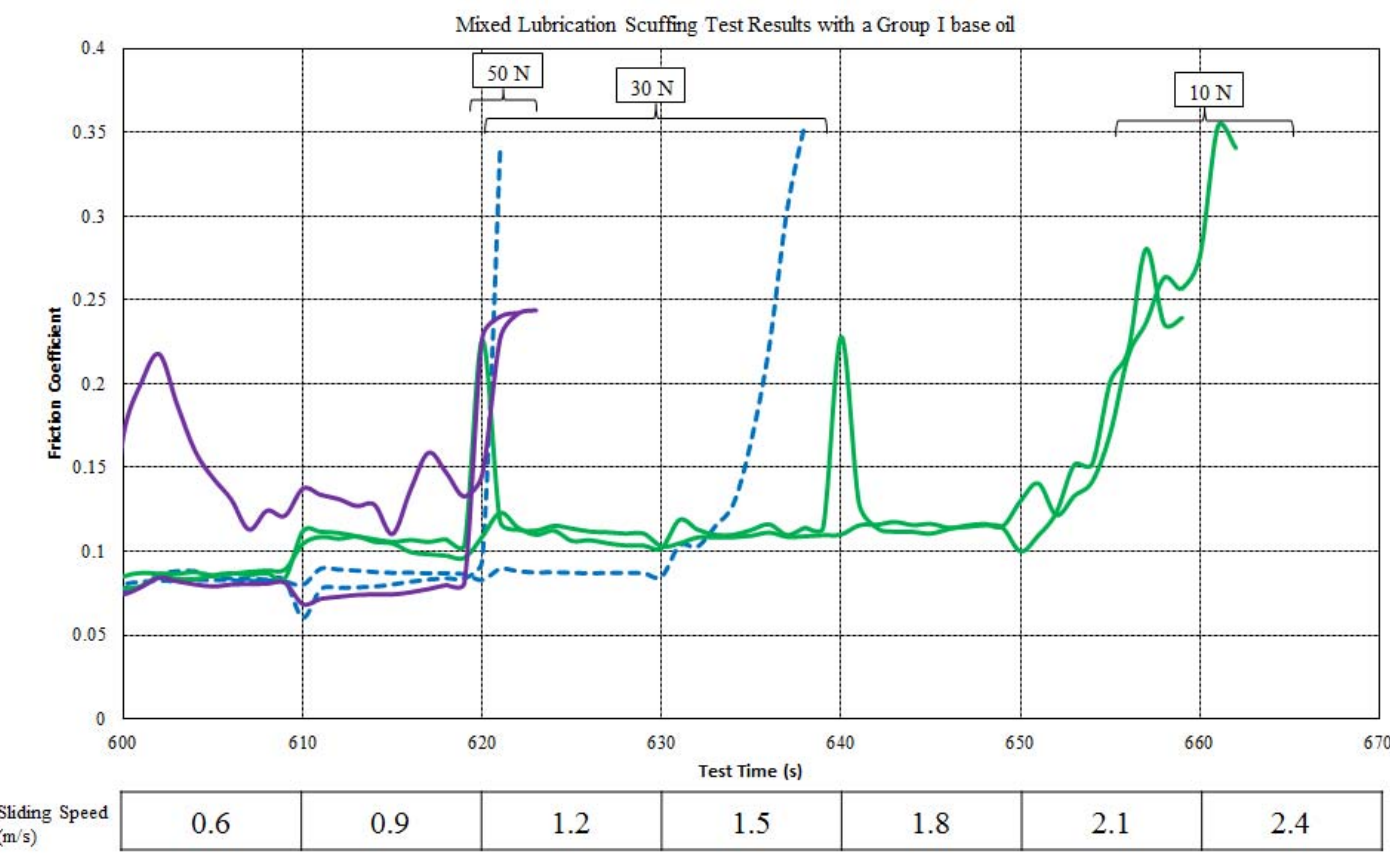

Figure 9: Example of the friction force measured during the mixed lubrication scuffing test at 50, 30 and $10 \mathrm{~N}$ load (repeat test are shown in the same colour)

The variability of these results shown by the error bars indicates the uncertainty of scuffing. This variability is likely to be the result of the catastrophic nature of 
scuffing, which can be initiated by minor differences in test conditions or materialsand in the absence of a sound understanding of this mechanism it is likely that the variation will continue for this and all scuffing test methods. The variation in the results will be discussed later in this article.

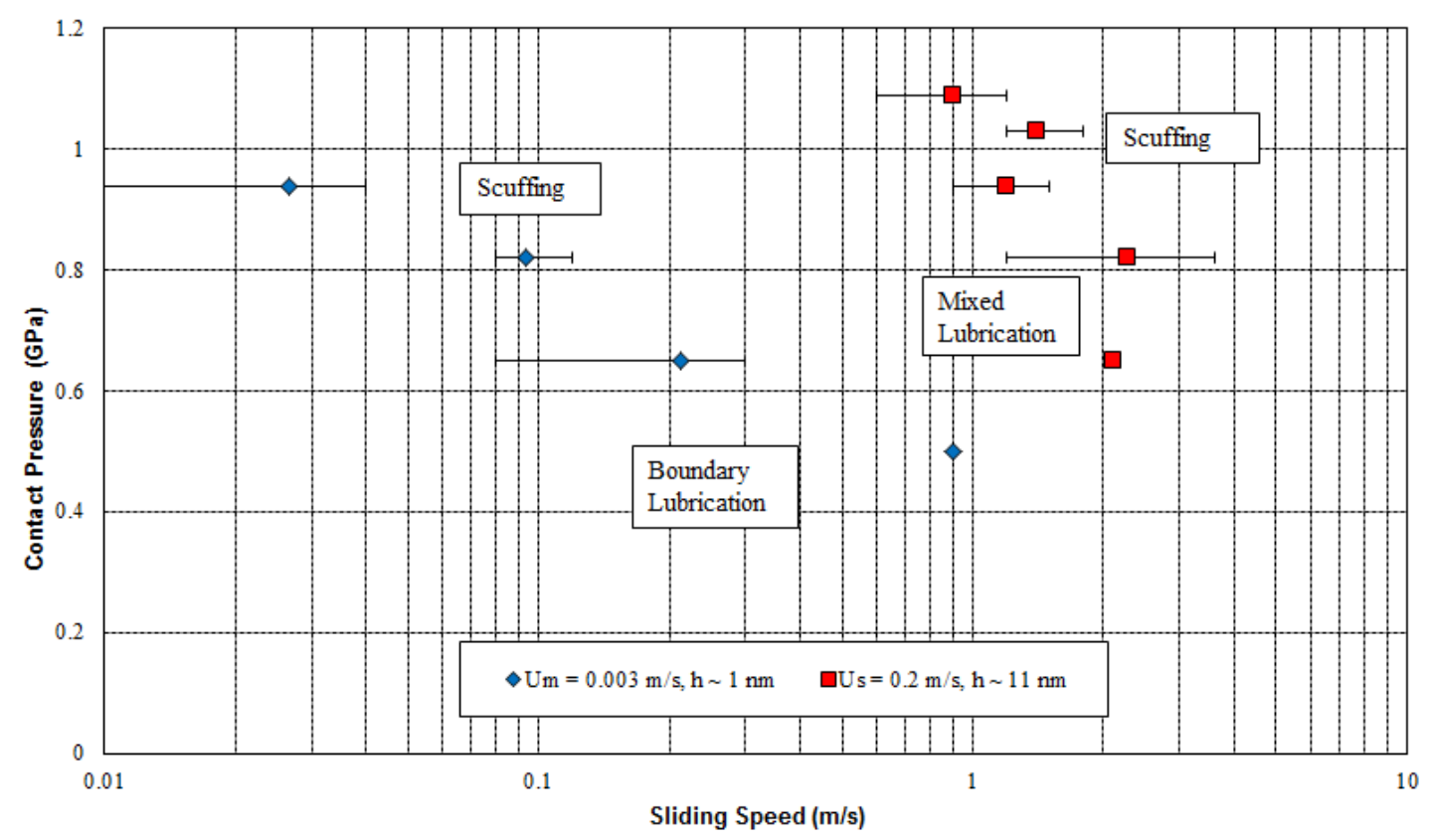

Figure 10: The conditions of scuffing for a Group I base oil during the boundary (Um = $0.003 \mathrm{~m} / \mathrm{s})$ and mixed $(\mathrm{Um}=0.2 \mathrm{~m} / \mathrm{s})$ lubrication scuffing tests

\subsection{Boundary Lubrication Regime Tests $(U=0.003 \mathrm{~m} / \mathrm{s})$}

Figure 11 shows some examples of scuffed areas produced on the disc samples in the boundary lubrication scuffing test.

When the scuffing failure occurs at low speeds it is possible to stop the test quickly, and then analyse the surfaces to gain an insight into the scuffing mechanism. Sometimes only one scuffed area is found over the entire area of the disc, but even this small area ( $<1 \mathrm{~mm}$ in length) causes the dramatic increase in friction required to indicate scuffing in our test method. The location of the scuffed areas can be at the edge or in the middle of the wear track, and usually appears as many arrowheads in a line pointing towards the direction of sliding. The arrowheads are areas of metal which is slightly raised from the original surface, presumably formed by transfer of material from the counter surface, or by the deformation of the surface at the elevated temperatures during scuffing.

When the failure occurs at high speeds, the damage to the surfaces is extensive and fast. The entire contact area appears scuffed and the contact width is substantially wider than the nominal Hertzian contact width, even when the instrument is halted 
immediately on detecting scuffing. This indicates significant material loss, even in those brief seconds between the onset of scuffing and the halting of the sliding motion.

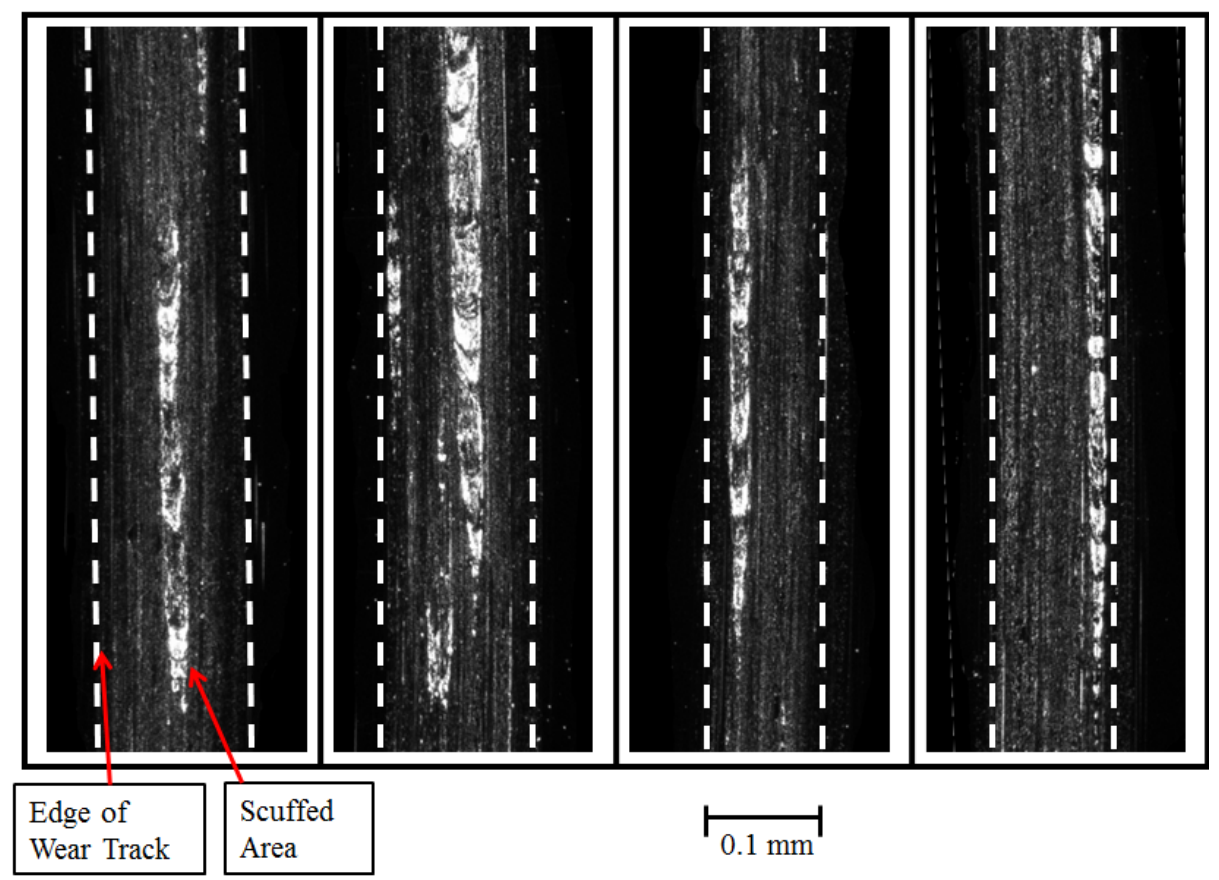

Figure 11: Microscope images showing scuffed regions on the disc specimens

Figure 12 shows the raw friction results for the $30 \mathrm{~N}$ load test $(\sim 0.95 \mathrm{GPa})$ when lubricated with the three base oils and the FM blend.

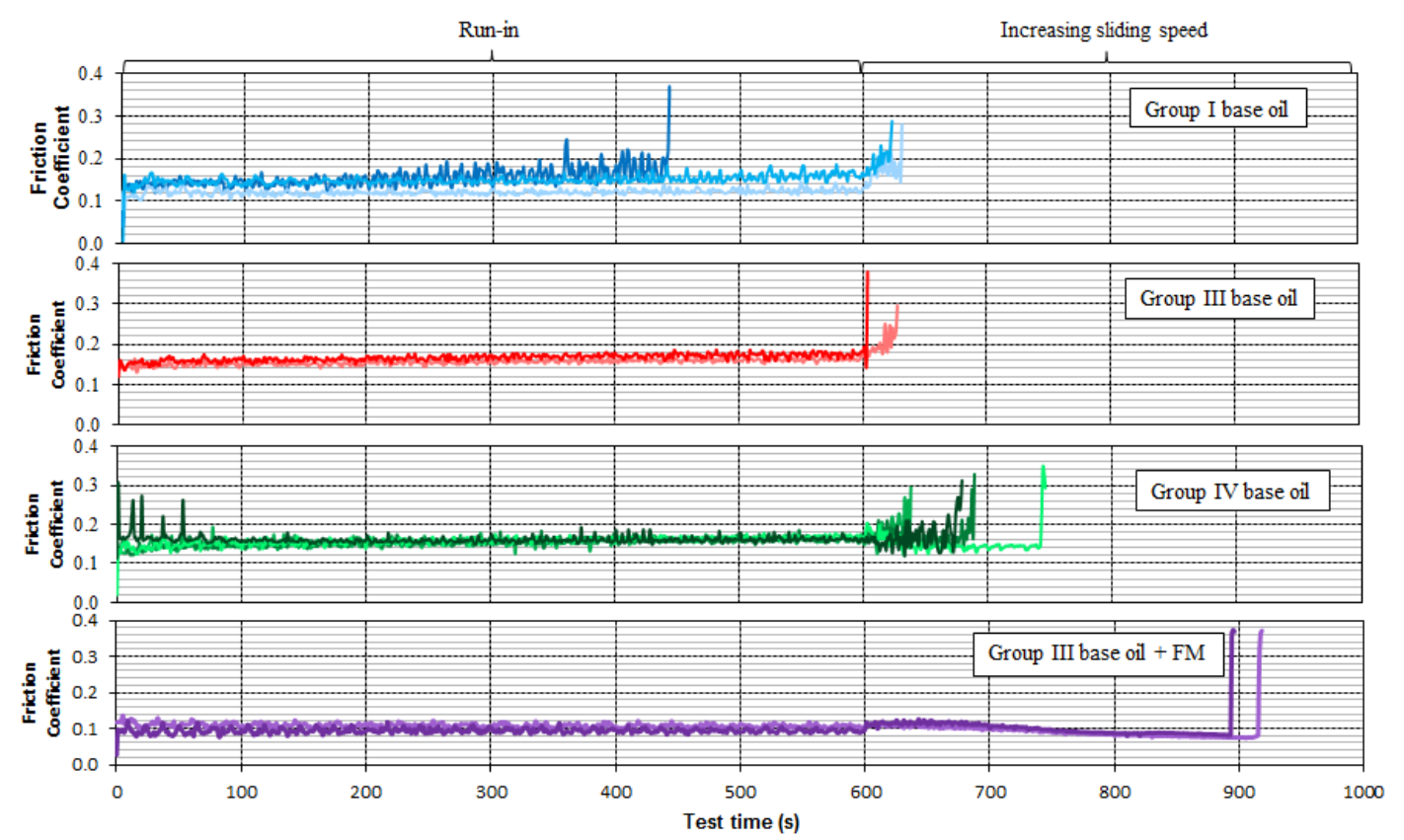

Figure 12: Examples of the friction data recorded during the boundary lubrication scuffing test at $30 \mathrm{~N}$ load for three base oils and a friction modifier blend 
The Group I base oil (SN150) showed scuffing at 0.01 (during run-in), 0.03 and 0.04 $\mathrm{m} / \mathrm{s}$ sliding speeds. The Group III base oil (Nexbase 3043) had a similar performance, failing at 0.02 and $0.04 \mathrm{~m} / \mathrm{s}$ sliding speed. The Group IV base oil (PAO 4) had better resistance to scuffing, failing at sliding speeds between 0.1 and $0.3 \mathrm{~m} / \mathrm{s}$. Adding a FM additive reduced the measured friction coefficient and increases the scuffing performance, as expected, so that scuffing now occurs at around $2 \mathrm{~m} / \mathrm{s}$. It can be seen that there is no noticeable step change in friction coefficient between sliding speed steps

These tests have been repeated using the boundary lubrication scuffing test at 10, 20 and $40 \mathrm{~N}$ load (0.65, 0.82 and $1.03 \mathrm{GPa}$ contact pressures, respectively) and the results are presented in Figure 13 as contact pressure and sliding speed at the point of scuffing. The scuffing performances of the base oils, although similar, do show a trend, where Group $\mathrm{I}<$ Group III $<$ Group IV in terms of scuffing performance. At a pressure of $0.65 \mathrm{GPa}(10 \mathrm{~N}$ load) the sliding speed needed to induce scuffing is approximately a factor of 10 higher than the $1 \mathrm{GPa}(40 \mathrm{~N}$ load $)$ test. The addition of a friction modifier additive to the Group III base oil has a marked effect on the scuffing performance.

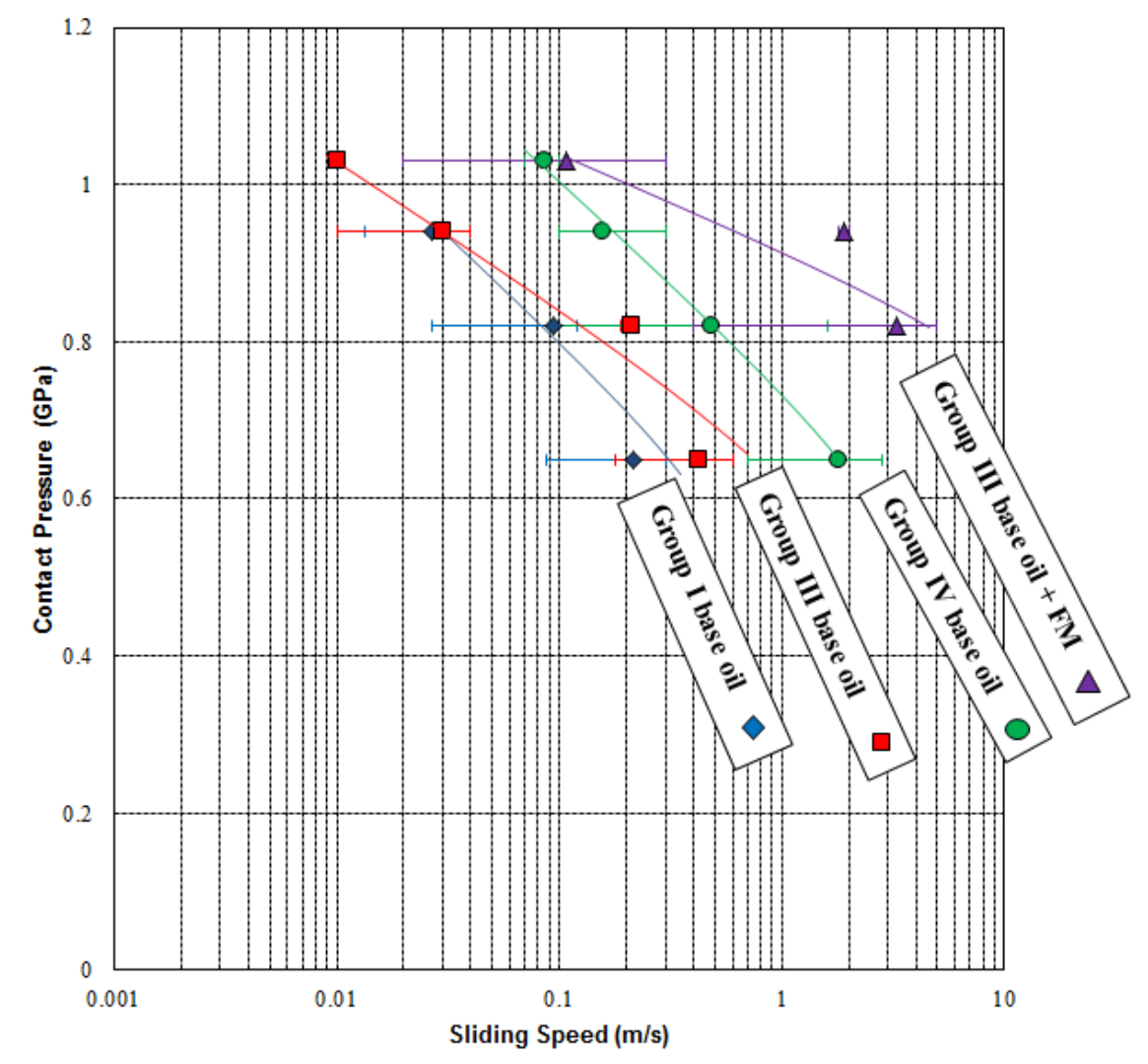

Figure 13: The conditions for scuffing during the boundary lubrication scuffing test for three base oils and a friction modifier blend 
The results for the EP additive blend in the boundary lubrication regime test are not included as this oil showed substantial corrosion and wearing during the test, which was indicated by a high friction coefficient and substantial material loss and discoloration. This made determination of the point of scuffing difficult and inaccurate. The addition of a corrosion inhibitor or other competing surface additives to the EP formulation should prevent substantial corrosion and allow this method to be used.

\subsection{Mixed Lubrication Regime Tests $(U=0.2 \mathrm{~m} / \mathrm{s})$}

Figure 14 shows the friction coefficient measured for the base oil and a EP additive blend using the mixed regime test at $30 \mathrm{~N}$ load.

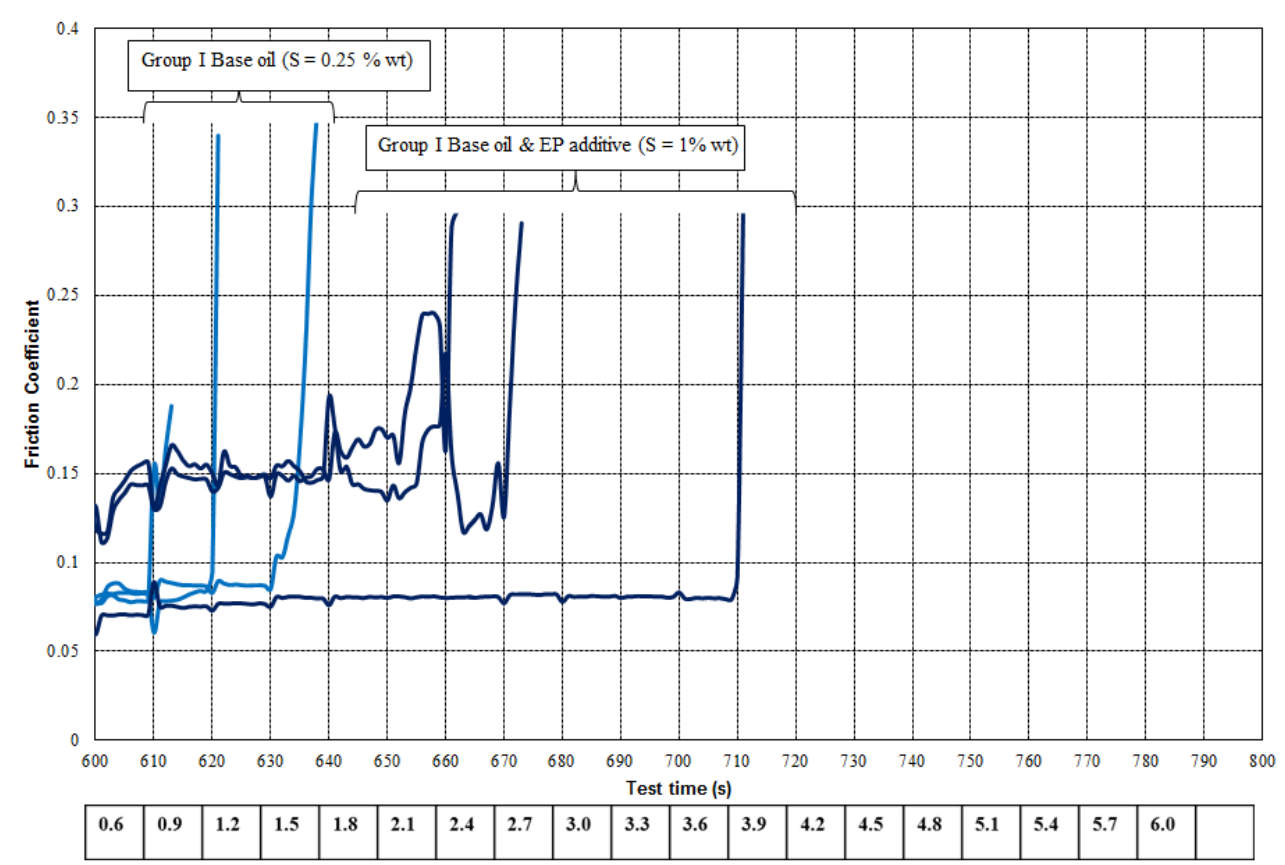

Figure 14: The friction coefficient recorded during the mixed lubrication scuffing test $(\mathrm{Um}=0.2 \mathrm{~m} / \mathrm{s})$ for a Group I base oil and a Group I base oil + EP additive at $30 \mathrm{~N}$ load (repeat test are shown in the same colour)

The EP additive increases the measured friction and also the sliding speed needed to induce scuffing. The same mixed regime test has been conducted at 20, 40 and $50 \mathrm{~N}$ loads with the Group I base oil and the Group I base oil + EP additive blend and the results are summarised in Figure 15 in terms of the contact pressure and sliding speed needed to induce scuffing for each test. Also shown are the results for the Group IV base oil which contains a negligible concentration of sulphur. There is a clear separation between the performance of the three oils. The Group IV base oil shows scuffing during the run-in procedure of the test over a range of loads, whereas the Group I base oil has better resistance to scuffing, probably from the active sulphur 
compounds within the oil. Increasing the sulphur concentration by the addition of an EP additive increases the scuffing performance further.

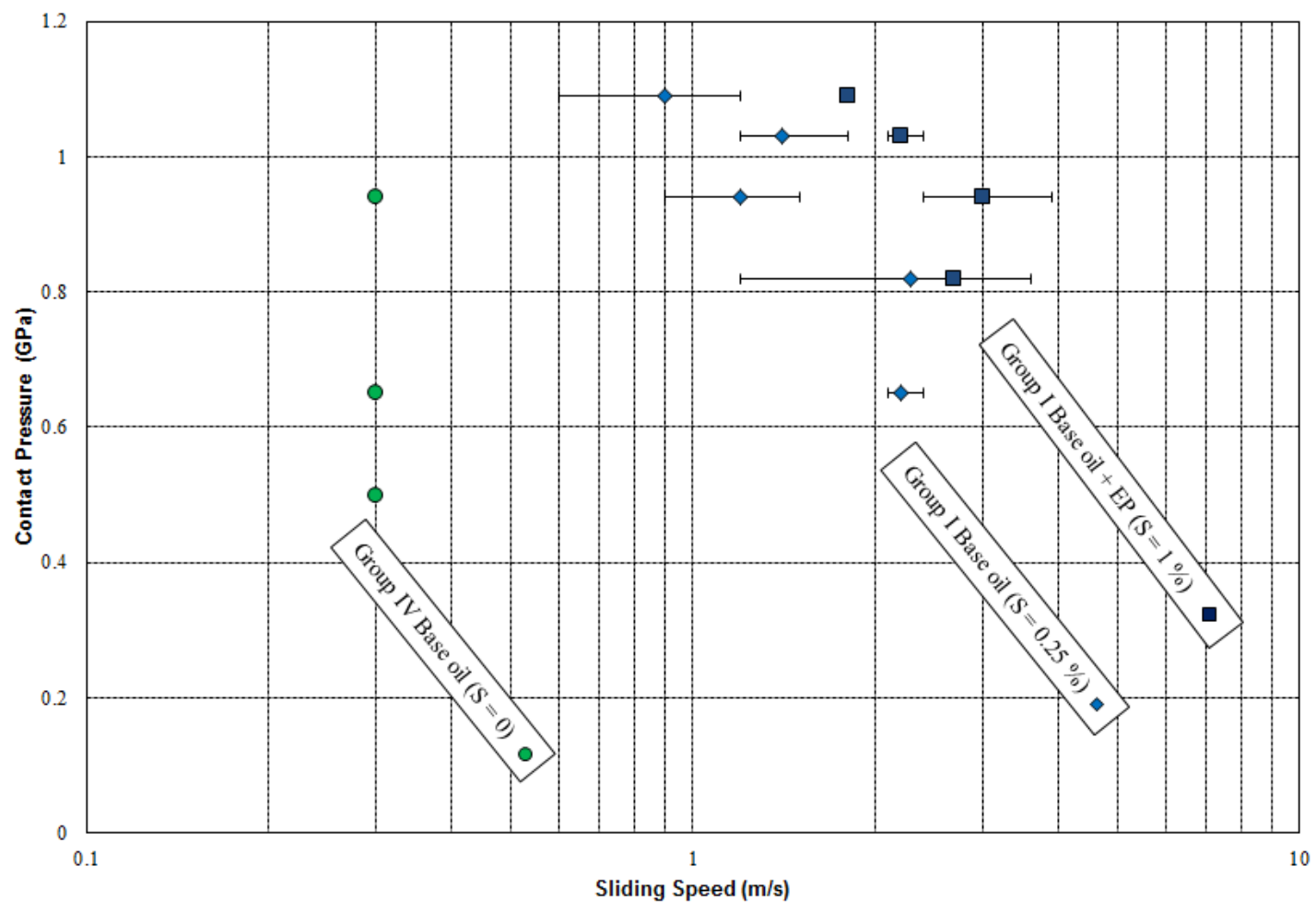

Figure 15: The conditions required for scuffing during the mixed lubrication scuffing test $(\mathrm{Um}=0.2 \mathrm{~m} / \mathrm{s}, \mathrm{h} \sim 12 \mathrm{~nm})$

Figure 16 shows friction coefficient measured during the mixed regime test for the Group III base oil and the Group III + FM oil. The addition of the FM reduces the measured friction and increases the sliding speed needed to induce scuffing. Figure 17 summarises the results for the Group III base oil and Group III + FM oil blend. The friction modifier additive increases the scuffing resistance of the base oil.

\section{DISCUSSION}

We have demonstrated a scuffing method which uses a contra-rotating contact at constant applied load with gradually increasing sliding speed. In this section we discuss the theory and assumptions made in this article, and also discuss some of the results generated by the specific test oils.

\subsection{Film Thickness Calculations}

It is possible to estimate the central elastohydrodynamic film thickness present in these scuffing tests using conventional EHD film thickness equations. However it must be emphasise that such estimates are only approximate. Such equations are developed for low slide-roll ratios and it is known that EHD film thickness decreases with increasing slide-roll at slide-roll ratios above about 50\% [20]. Also these 
equations are based on full film EHD conditions rather than the boundary or mixed EHD conditions of the two test protocols. The estimates do, however, provide a useful upper bound.

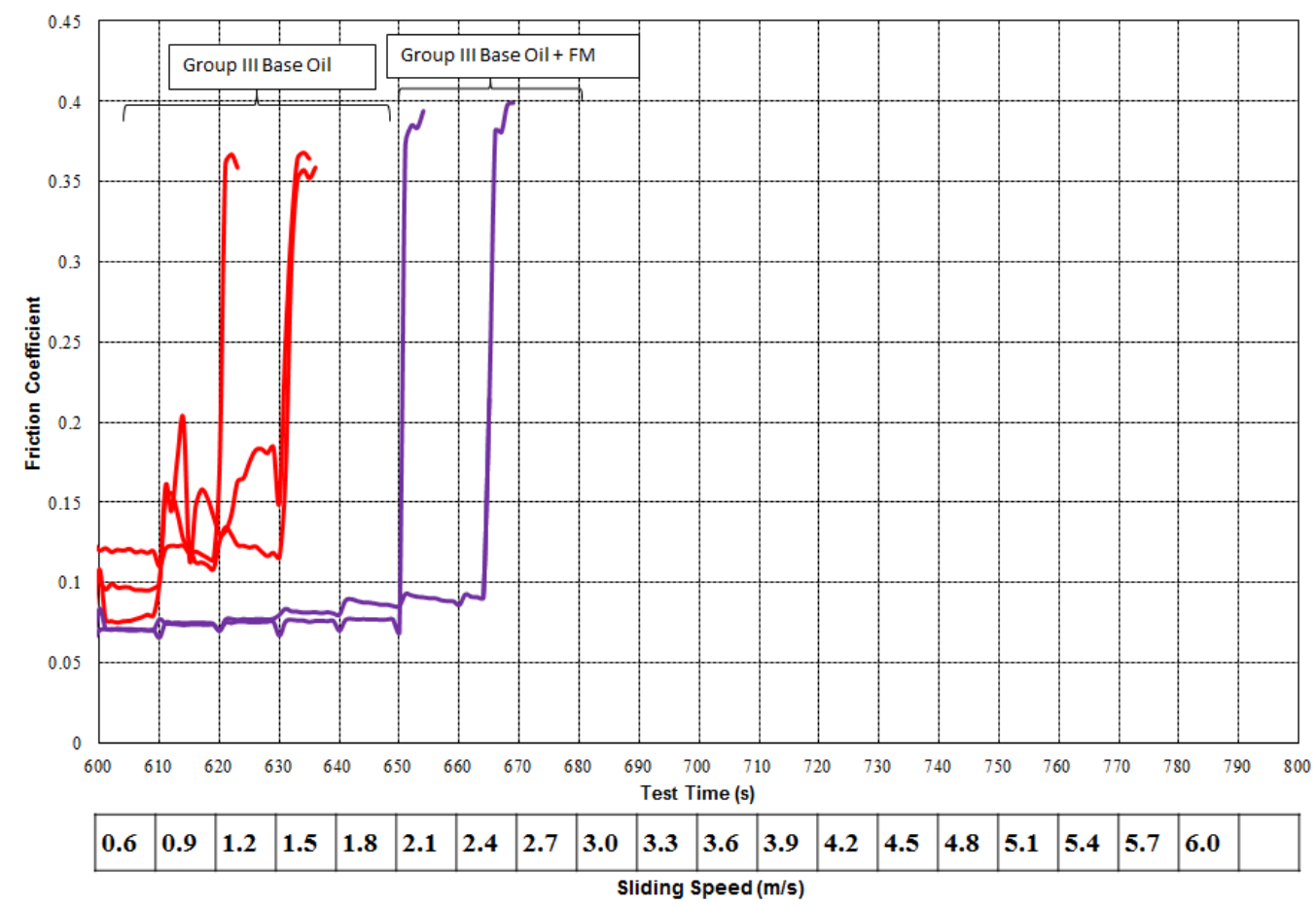

Figure 16: The friction coefficient recorded during the mixed lubrication scuffing test $(\mathrm{Um}=0.2 \mathrm{~m} / \mathrm{s})$ for a Group I base oil and a Group I base oil + EP additive (repeat test are shown in the same colour)

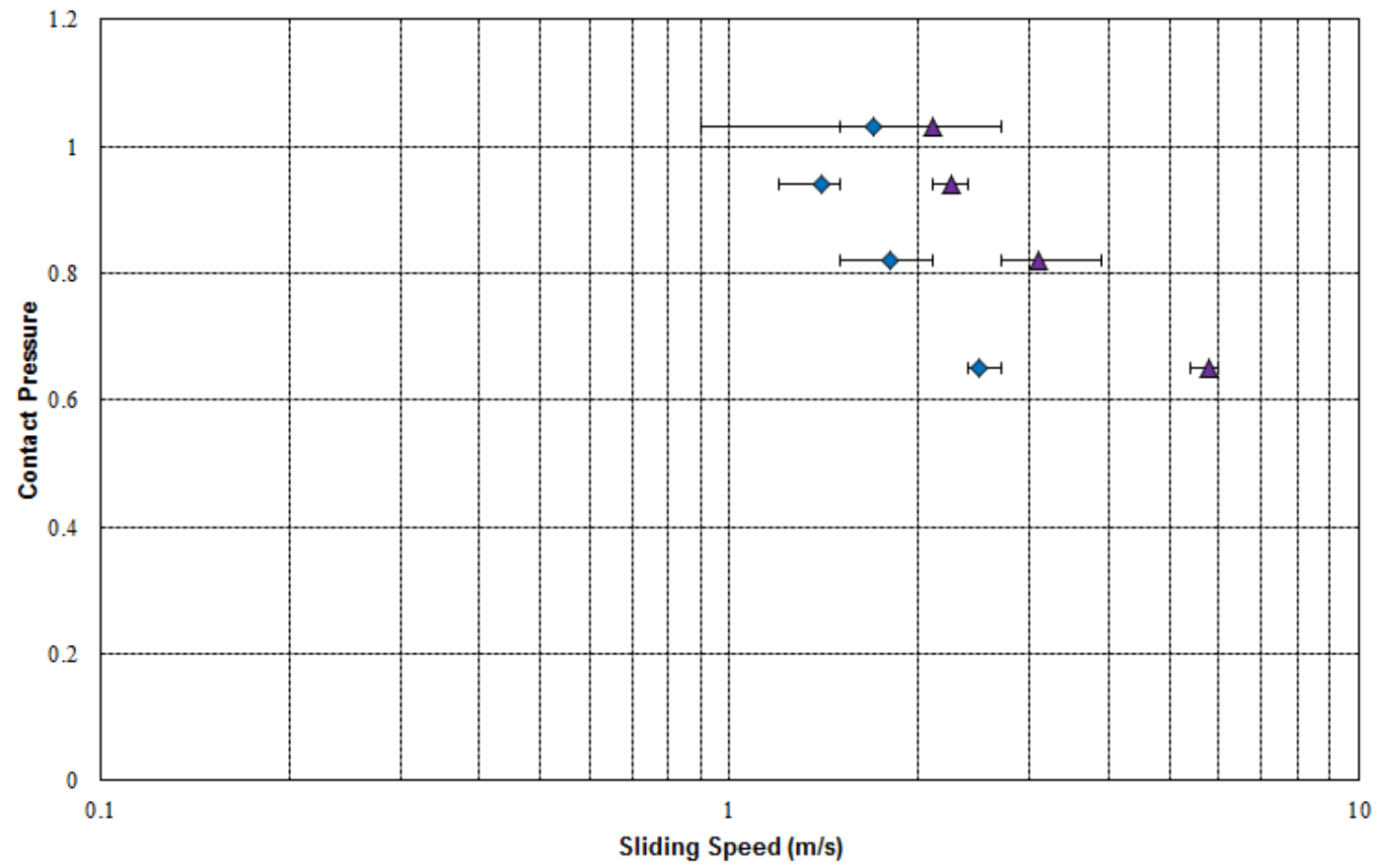

Figure 17: The conditions for scuffing for a Group III base oil and a Group III base oil + FM additive using the mixed lubrication scuffing test $(\mathrm{Um}=0.2 \mathrm{~m} / \mathrm{s}, \mathrm{h} \sim 10 \mathrm{~nm})$ 
For the geometry and materials used in this study, the theoretical, central elastohydrodynamic film thickness, $h$ reduces to;

$h \approx 1540(U \eta)^{0.67} \mathrm{~nm}$

where $U$ is the entrainment speed in $\mathrm{m} / \mathrm{s}$ and $\eta$ is the dynamic viscosity in Pas. This assumes an applied load of $10 \mathrm{~N}$ and a representative lubricant pressure-viscosity coefficient of $17 \times 10^{-9} \mathrm{~m}^{2} / \mathrm{N}$. The reduced radius ( $\mathrm{R}^{\prime}$ ) and reduced Young's modulus (E') are calculated as $4.8 \times 10^{-3} \mathrm{~m}$ and $2.3 \times 10^{11} \mathrm{~Pa}$ respectively. Thus for a lubricant of viscosity 0.003 Pas at $U=0.003 \mathrm{~m} / \mathrm{s}, h \approx 1 \mathrm{~nm}$. This is far less than the composite surface roughness of approximately $15 \mathrm{~nm}$. For an entrainment speed $U=0.2$, in the mixed lubrication scuffing test, the theoretical film thickness increases to $h \approx 11 \mathrm{~nm}$, which is comparable to the composite surface roughness. These estimates thus confirm that the low entrainment speed test operates in boundary lubrication while the higher entrainment speed test is probably mixed boundary-EHD.

One potential complication to the above estimates is that there is some evidence that a small EHD film can exist between contra-rotating bodies, such as those in a retainerless ball bearing. A study by Shogrin [21] has measured a small film ascribed to lubricant entrainment in a contra-rotating contact under zero entrainment velocity (ZEV) conditions. Guo [22] has modelled a ZEV contact and compared the results to an experimental study of a similar contact by Yagi [23]. Both show a localised elastic deformation of the steel surfaces in the centre of the contact point, referred to as a dimple. This suggests that the classical EHD theory which we have assumed in this work may need further investigation when applied to very low entrainment speed but high sliding speed conditions. The high shear rate of the contra-rotating contact is also expected to complicate the film thickness calculation.

Making accurate measurements of film thickness under contra-rotating conditions is challenging, as it is difficult to use the conventional optical interferometry EHD method [24] due to the rapid destruction of the silica coating under the high sliding conditions. In principle a capacitance or ultrasonic method might be used but these are not well suited to study lubricant films of thickness 1 to $10 \mathrm{~nm}$.

\subsection{Increasing speed vs increasing load}

To estimate the conditions at which scuffing is induced in a particular system, the speed or load can be gradually increased until scuffing occurs. When an increasing load test is used, a characteristic high friction peak is seen at the start of every load stage. This is believed to originate from a new area of steel specimen coming into contact as the increased load results in an increased contact width, with the newly contacting surface not initially having a protective tribofilm. Scuffing is thus likely to 
originate at the edge of the contact in the step load tests. This effect is not generally seen in increasing sliding speed tests which is why these are used predominantly in this study.

\subsection{Base oil behaviour}

One noteworthy feature of the scuffing results is that in the boundary scuffing test the Group I oil scuffed more easily than the Group IV oil, with the Group III oil being intermediate. However in the mixed lubrication test the order was reversed, with the Group IV oil scuffing more easily than the Group I and Group III oil. In general one would expect that base oils with active sulphur constituents, i.e. Group I, to have greater scuffing performance, due to their ability to smooth the surface and form a protective boundary films. There are two possible reasons for this reversal:

1. If the "dimple" mechanism is occurring in our contact, the Group IV base oil (synthetic PAO) may be preventing scuffing in a similar way to that described in the work by Shogrin [21]. The reason for the superiority of the PAO is unknown, but may be clarified as the "dimple" mechanism is studied further. It is likely to be based on the physical properties of the base oils, which in turn will affect their ability to form a viscous film in the contact and the observed dimple response. In the mixed lubrication scuffing test, when the entrainment speed is $0.2 \mathrm{~m} / \mathrm{s}$, the "dimple" effect may be lost.

2. Different run-in procedures are used for the two tests. The sliding speeds of the two test sequences during the run-in are 0.3 and $0.01 \mathrm{~m} / \mathrm{s}$ for the mixed and boundary regime test respectively. So during the mixed regime sequence the sliding distance experienced by the samples is significantly higher during the runin period, which may afford the active sulphur compounds within the Group I and Group III base oils greater opportunity to reduce the roughness of the surfaces and form a protective $\mathrm{FeS}_{2}$ layer.

\subsection{Action of FM and EP additives}

Friction modifiers and extreme pressure additives are used here to enhance the scuffing performance of the base oils. Both are shown to increase the scuffing performance, but their actions at the metal surfaces differ.

EP additives have two mechanism of preventing scuffing:

1. The sulphur containing molecules can react quickly with any exposed nascent metal surface, preventing any metallic bonding between metal atoms across the sliding interface. This is indicated by the transient nature of the high friction spikes in our test (Figure 14). The friction spikes are presumably due to the exposure of the reactive nascent metal below the FeO surface, causing a 
temporary high friction interface. The sulphur compounds in the lubricant then quickly react with the exposed surface, preventing significant scuffing. These high friction spikes are not observed for the PAO base oil, which contains no reactive sulphur compounds.

2. The $\mathrm{FeS}_{2}$ layer is easily sheared from the surface [25] helping to smooth the metal surface, and reduce asperity interactions between the surfaces. This will reduce the likelihood of any two asperities meeting and initiating scuffing.

Organic friction modifiers additives, such as the one used in this study, physisorb or chemisorb to metal surfaces, forming protective boundary films. These films reduce friction between two sliding bodies, by reducing contact between the surface asperities and replacing it with a low shearing interface [26, 27]. The FM film prevents scuffing by preventing asperity contact and maintaining a low friction contact, and thus low heat generation. During shearing of the FM film, part of the film can be removed, but as the layers are in contact with a lubricant the boundary layers can be replenished by the free surfactant in the lubricant. The FM film adsorption and desorption is thermally governed, thus above a critical flash temperature the polar molecules may become sufficiently depleted or disoriented, resulting in an unprotected metal surface and scuffing [10].

\subsection{Test variability}

One clear feature that emerges from this study is the large variability in results, even using closely-controlled test conditions and specimens and with a run-in period. This variability is not generally found in friction or wear measurements and is more reminiscent of the statistical nature of fatigue tests. It almost certainly reflects the criticality of scuffing, which is not based on any average response but is triggered by some critical condition, from which scuffing then proceeds catastrophically. This may be a slight variation in surface roughness, at a level which is not important in friction or wear tests, or even the chance presence of hard inclusions within the contact track for some specimens but not others.

The variability of this contra-rotating scuffing test was explored by carrying out fifteen repeated tests on the Group III base oil at $U_{\mathrm{m}}=0.2 \mathrm{~m} / \mathrm{s}$ and $30 \mathrm{~N}$ load. The sliding speed at which the tests failed are shown in Table 6 and have been fitted to the general Weibull distribution [28], as is conventional done when analysing rolling contact fatigue data. The results show a Weibull slope of $\beta=3.1$, which is closer to the normal distribution region of the Weibull form than the type of skewed distribution found in fatigue experiments, where $\beta$ is more typically 2 . 


\begin{tabular}{|l|c|}
\hline \multicolumn{2}{|l|}{ Table 6: Repeatability study (Um $=\mathbf{0 . 2}$} \\
m/s, Load $=\mathbf{3 0}$ N, Group III base oil \\
\hline Test & Sliding speed at scuffing (m/s) \\
\hline 1 & 1.5 \\
\hline 2 & 1.2 \\
\hline 3 & 1.5 \\
\hline 4 & 3.0 \\
\hline 5 & 1.5 \\
\hline 6 & 1.8 \\
\hline 7 & 1.5 \\
\hline 8 & 1.8 \\
\hline 9 & 1.8 \\
\hline 10 & 1.2 \\
\hline 11 & 1.8 \\
\hline 12 & 1.5 \\
\hline 13 & 1.8 \\
\hline 14 & 3.9 \\
\hline 15 & 2.4 \\
\hline
\end{tabular}

\subsection{Relevance of test}

Scuffing generally occurs in real components when the operating conditions stray outside their design limits, for example the temperature or load is too high, or the lubricant contains a high concentration of contaminants or soot. This can lead to a drop in EHD film thickness and so the boundary lubricant additives must protect against scuffing. The boundary film may then temporarily prevent the surfaces from scuffing, in the hope of a return to normal operating conditions. The limits of this boundary or mixed regime in preventing scuffing can be determined using this test method, giving design engineers better insight when designing a lubricated system, and the possibility of providing total lubricated protection of the system, even in extreme conditions.

The scuffing limits, such as those shown in Figures 15 and 17, can be used by design engineers to specify the minimum performance required of a lubricant destined for a particular application. i.e. if a particular system is known to operate at a pressure of $0.8 \mathrm{GPa}$, the sliding speed limit could be imposed as $1 \mathrm{~m} / \mathrm{s}$. Thus even if the EHD 
film of the system is lost, the boundary lubrication film may prevent scuffing, at least temporarily.

\section{SUMMARY}

A new scuffing test is described in this article that uses contra-rotating surfaces to limit EHD films even at high sliding speeds (up to $6 \mathrm{~m} / \mathrm{s}$ ). We have demonstrated this novel technique and show how the method can be used to differentiate the scuffing resistance of different lubricated systems. Specifically we used test samples manufactured from AISI 52100 steel and simple base oil blends (Group I, III \& IV base oils with EP and FM additives). The results show that:

- Scuffing is dependent on the entrainment speed and thus the film thickness higher sliding speeds are needed to induce scuffing in a system which is operating in the mixed regime as opposed to the boundary regime.

- The sulphur compounds found naturally within Group I base oils can inhibit scuffing.

- EP and FM additives can improve the scuffing performance of the base oils

- The variation of our results are normally distributed and may be due to minor differences on the morphology, composition or microstructure of the surfaces of the metal samples

The scuffing tendency can be portrayed as scuffing design maps (contact pressure against sliding speed), similar to previous transition diagrams [6]. The critical zones of scuffing can then be easily identified and separated from the safe operating condition for a particular system.

The contra-rotation method offers two major advantages over current methods:

- it achieves very high sliding speeds while maintaining low entrainment speeds

- it studies the scuffing resistance of lubricants independent of the latters' viscosity

This will be useful to the tribology community as this method has the potential to allow the development of better lubricants, steels and coatings which have a better scuffing resistance. This in turn will allow the development of smaller and lighter machine components which can operate with greater efficiency.

\section{ACKNOWLEDGMENTS}

The authors wish to thank two research students, Christopher Salt and Joshua Maguire, who worked on the early development of this contra-rotating technique at 
Imperial College. We also express our gratitude to Amir Kadiric, Mark Fowell and Matt Smeeth for their input to this work.

\section{REFERENCES}

[1] F.F. Musgrave, The development and lubrication of the automotive hypoid gear, J. Inst. Pet. 32 (1946) 32-44

[2] G. Neely, Extreme-Pressure Lubricants Testing, SAE Technical Paper 360125, (1936) doi:10.4271/360125

[3] ASTM Standard test method for measurement of extreme-pressure properties of lubricating fluids (four-ball method), ASTM D2783 - 03(2009).

[4] ASTM Standard test method for measurement of extreme-pressure properties of lubricating fluids (Timken Method), ASTM D2782 - 02(2014).

[5] O.Bridgeman, The present status of the extreme pressure lubrication problem. SAE Technical Paper 340011, (1934) doi:10.4271/340011

[6] A.W.J de Gee, A. Begelinger, G. Salomon, Failure mechanisms in sliding lubricated concentrated contacts, Proc. $11^{\text {th }}$ Leeds-Lyon Symp. on Tribol, Mixed Lubrication and Lubricated Wear, Leeds, 1984, 105-124.

[7] D.J. Schipper, A.W.J. de Gee, Lubrication modes and the IRG Transition Diagram, Lubr. Sci. 8, (1995) 27-35. DOI: 10.1002/1s.3010080104

[8] W.F. Bowman, G.W. Stachowiak, A review of scuffing models, Tribol. Lett. 2, (1996) 113-131. DOI: 10.1007/BF00160970

[9] H. Blok, Theoretical study of temperature rise at surfaces of actual contact under oiliness lubricating conditions, Proc. Gen. Discuss. Lubr. Inst. Mech. Eng. London, (1937) 222-235.

[10] H. Spikes, A. Cameron, Scuffing as a desorption process - an explanation of the Borsoff effect, ASLE Trans. 17, (1974) 92-96. DOI: 10.1080/ 05698197408981442

[11] A. Dyson, The Failure of Elastohydrodynamic Lubrication of Circumferentially Ground Discs, Proc. Inst. Mech. Eng. 190. (1976) 677-711. DOI: 10.1243/ PIME_PROC_1976_190_074_02

[12] H.S. Cheng, A. Dyson, Elastohydrodynamic Lubrication of CircumferentiallyGround Rough Disks, ASLE Trans. 21, (1978) 25-29 DOI: 10.1080/ 05698197808982858 
[13] J. Enthoven, H.A. Spikes, Infrared and visual study of the mechanisms of scuffing, Tribol. Trans. 39 (1996) 441-447. DOI:10.1080/ 10402009608983550

[14] J. Hershberger, O.O. Ajayi, J. Zhang, H. Yoon, G.R. Fenske, Evidence of scuffing initiation by adiabatic shear instability, Wear 258, (2005) $1471-1478$. DOI: $10.1016 /$ j.wear.2004.10.010

[15] D. Dowson, B.J. Hamrock, Ball Bearing Lubrication. The Elastohydrodynamics of Elliptical Contacts. John Wiley \& Sons 1981.

[16] H. Blok, Gear wear as related to viscosity of gear oils, Proc. Summer Conference - MIT, Mech. Wear, June 1948, publ. ASME (1948) 199-227.

[17] L.V. Wedeven, Load capacity method, Wedeven Associates Inc. website www.wedeven.com.

[18] J. Fan, H.A. Spikes, New test for mild lubricated wear in rolling-sliding contacts, Tribol. Trans. 50, (2007) 145-153. DOI: 10.1080/10402000701255476

[19] J. Maguire, Development of a new scuffing test, Imperial College 4M Project Report, (2007)

[20] M. Smeeth, H.A. Spikes, The influence of slide/roll ratio on the film thickness of EHD contact operating within the mixed lubrication regime, Proc. $22^{\text {nd }}$ Leeds-Lyon Symp. Tribol, (1995).

[21] B.A. Shogrin, W.R. Jones Jr, E.P. Kingsbury, M.J. Jansen, J.M. Prahl, Experimental study of load carrying capacity of point contacts at zero entrainment velocity, NASA/TM-1998-208650 (1998)

[22] F. Guo, P.L. Wong, P. Yang, K. Yagi, Film formation in EHL point contacts under zero entraining velocity conditions, Tribol. Trans., 45 (2002), 521-530. DOI: $10.1080 / 10402000208982583$

[23] K. Yagi, K. Kyogoku, T. Nakahara, Temperature measurement of oil film and surface in point contact EHL under high slip ratio condition, Proc. Int. Tribol. Conf. (2000) Nagasaki, 375-385.

[24] H.A. Spikes, Sixty years of EHL, Lubr. Sci. 18, (2006) 265-291. DOI: $10.1002 / 1 \mathrm{~s} .23$

[25] M.N. Najman, M. Kasrai, G.M. Bancroft, X-ray absorption spectroscopy and atomic force microscopy of films generated from organosulfur extreme-pressure (EP) oil additives, Tribol. Lett. 14, (2003) 225-235. DOI: 10.1023/ A:1022650516272 
[26] F. Bowden, D. Tabor, The friction and lubrication of solids, Clarendon Press, Oxford, 1986.

[27] I. Iliuc, Tribology of thin layers, Elsevier, Romania, 1974.

[28] W. Weibull, A statistical distribution function of wide application, ASME pap. 51-A-6 (1951). 